\title{
Assembly of Carbon Nanotube Sheets
}

\author{
Mei Zhang ${ }^{1}$ and Ray Baughman ${ }^{2}$ \\ ${ }^{1}$ Florida State University \\ 2University of Texas at Dallas \\ The United State of America
}

\section{Introduction}

Over the past decades, carbon nanotubes (CNTs) have been actively explored as building blocks for next-generation electronics (Tans et al., 1998; Bachtold et al., 2001; Misewich et al., 2003), optoelectronics, and sensors (Kong et al., 2000; Xia et al., 2003; T. Zhang, 2008), including flexible and transparent devices ( Ju et al., 2007) as well as stretchable devices (Xu et al., 2011). A critical step in constructing CNT-based devices is assembly of CNTs on a substrate or free-standing for device fabrication, which include alignment, density control, and transfer. Scalable and controlled assembly of CNTs synthesized with diverse methods (e.g., solution fabrication or solid-state fabrication methods) on diverse substrates (e.g., silicon, plastics, rubbers, etc) or free-standing presents a major fabrication challenge that must be overcome if CNTs are to be utilized in practical applications. For assembling CNTs into thin films (or called sheet, buckypaper), there are several different methods or processes in different conditions (e.g., solution or solid-state processes) (Hu et al., 2010). Solution processes start with the CNTs in powder form; the powder is dispersed in an appropriate solvent with or without functionalization. The CNT films (buckypapers) are usually made using versions of the ancient art of paper making, by typically long-time filtration of nanotubes dispersed in solvent and peeling the dried nanotubes as a layer from the filter (Rinzler et al., 1998; Endo et al., 2005). Buckypaper normally has a laminar structure with a random orientation of the bundles of the nanotubes in the plane of the film (Berhan et al., 2004). Interesting variations of the filtration route provide ultra-thin nanotube sheets that are highly transparent and highly conductive (Wu et al., 2004; $\mathrm{Hu}$ et al., 2004). While filtration-produced sheets are normally isotropic within the sheet plane, sheets having partial nanotube alignment result from applying high magnetic fields during filtration (Fischer et al., 2003). In other important advances, nanotube films have been fabricated by Langmuir-Blodgett deposition (Y. Kim et al., 2003), casting from oleum (Sreekumar et al., 2003), coating (Ago et al., 1999; Dan et al., 2009), and printing (Zhou et al., 2006; Unidym Inc, 2007). The solid-state processes generally have two approaches. One is to synthesize CNTs by floating catalyst chemical vapor deposition (CVD), either to deposit CNTs on a substrate inside the CVD chamber or to collect the CNT aerogel outside of the chamber on a special substrate and then densify it into a film (Y. Li et al., 2004; Martin, 2010). The catalysts are with the CNTs and the CNTs in the film are usually disoriented. The optimized process control lowers the impurities to less than $5 \mathrm{wt} \%$ in the film and a 1.2 meter wide and 10 meter long CNT film has been made (Nanocomp Tech. 2010). The other approach is to 
synthesize CNTs from the catalysts fixed on substrate to form a array either parallel to the substrate (Kong et al., 1998) or perpendicular to the substrate (also called vertical aligned CNT forest) which are fabricated into the CNT films after the synthesis process by the "domino pushing effect" motion (Ding et al., 2008; Pevzner et al., 2010) or drawing CNTs out of the forest (M. Zhang et al., 2004 \& 2005). The domino pushing of the CNT forest can efficiently ensure that most of the CNTs are aligned tightly in the film. Well aligned CNT sheets are obtained by drawing CNTs from the forest.

For fabricating sheets that have close to single nanotube properties, long nanotubes are needed. Solution fabrication methods work only for short nanotubes since the ability to disperse nanotubes into a liquid and to fabricate oriented nanotube sheets from liquid dispersions decreases with increasing nanofiber length. Solid-state fabrication methods do not disturb the length of the nanotubes and are the methods that benefit from long nanotubes. In this chapter, two processes for assembling well aligned and super-thin CNT sheets are presented. One is to produce a drawable CNT forest, which has special topology, by CVD and then draw CNTs out of forest to form a free-standing CNT sheet. Another process involves synthesis of a patterned CNT array on substrate by CVD and then knocking them down to form an aligned CNT sheet on substrate with the help of the solvent. The CNT growth and the conditions for making drawable CNT forests are discussed.

\section{Fabrication of CNT sheet}

Since the CNT sheets are fabricated directly from the forests, the synthesis of the CNT forest is an important step. In this chapter, the CNTs are multi-walled CNTs. The CNT forests were synthesized by catalytic CVD using hydrocarbon gas, acetylene or ethylene, as the carbon source (M. Zhang et al., 2004). The following is the basic process and conditions. The catalyst was a $\sim 3 \mathrm{~nm}$ thick iron film, which was deposited on a silicon substrate by electron beam evaporation. The substrates were set in the center of a quartz tube furnace. After heating up to $680^{\circ} \mathrm{C}$ in helium at one atmospheric pressure, 5 molar percent acetylene in helium was introduced at the total flow rate of $580 \mathrm{sccm}$. Within a few minutes, the dense and vertically aligned CNT forests were grown on substrates. After removing the forest, the substrate is still catalytically active and can be used to grow new forest, indicating a rootgrowth mode and the presence of the catalysts on the substrate. Based on scanning electron microscopy (SEM), transmission electron microscopy (TEM), and thermo-gravimetric analysis (TGA), the purity of the nanotube forests was very high ( more than $99 \%$ carbon in the form of CNTs), with less than $1 \mathrm{wt} \%$ iron and amorphous carbon, but more importantly, no carbon particles within the CNTs were observed. The CNT sheets are made from the $\mathrm{CNT}$ forests by two approaches, knocking down and drawing.

\subsection{Knocking down approach}

The schematic of the knocking down approach is shown in Fig. 1. The line arrays of thin Fe film was made by patterning the resist on Si substrate following the standard lithography process, depositing the catalyst thin film by electron beam evaporation and then the lifting off the resist mask. The Fe film cracked into nanoparticles as catalysts for CNT growth during the temperature ramp up in CVD process. The CNTs grew away from the catalyst particles and formed a thin wall array during the CVD process (Figs. 2a to 2c). The CNT wall is very thin, so it is transparent (Fig. 2a). The substrate with the array of CNT walls was 


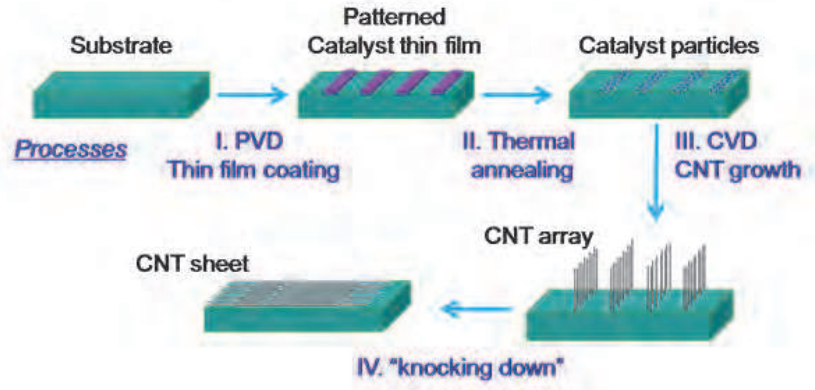

(a)

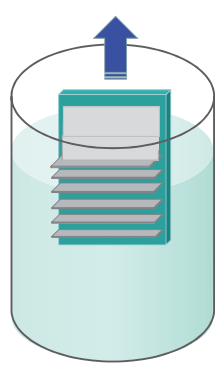

(b)

Fig. 1. Schematic experimental processes for making an aligned thin CNT film on substrate (a) and knocking down method (b).
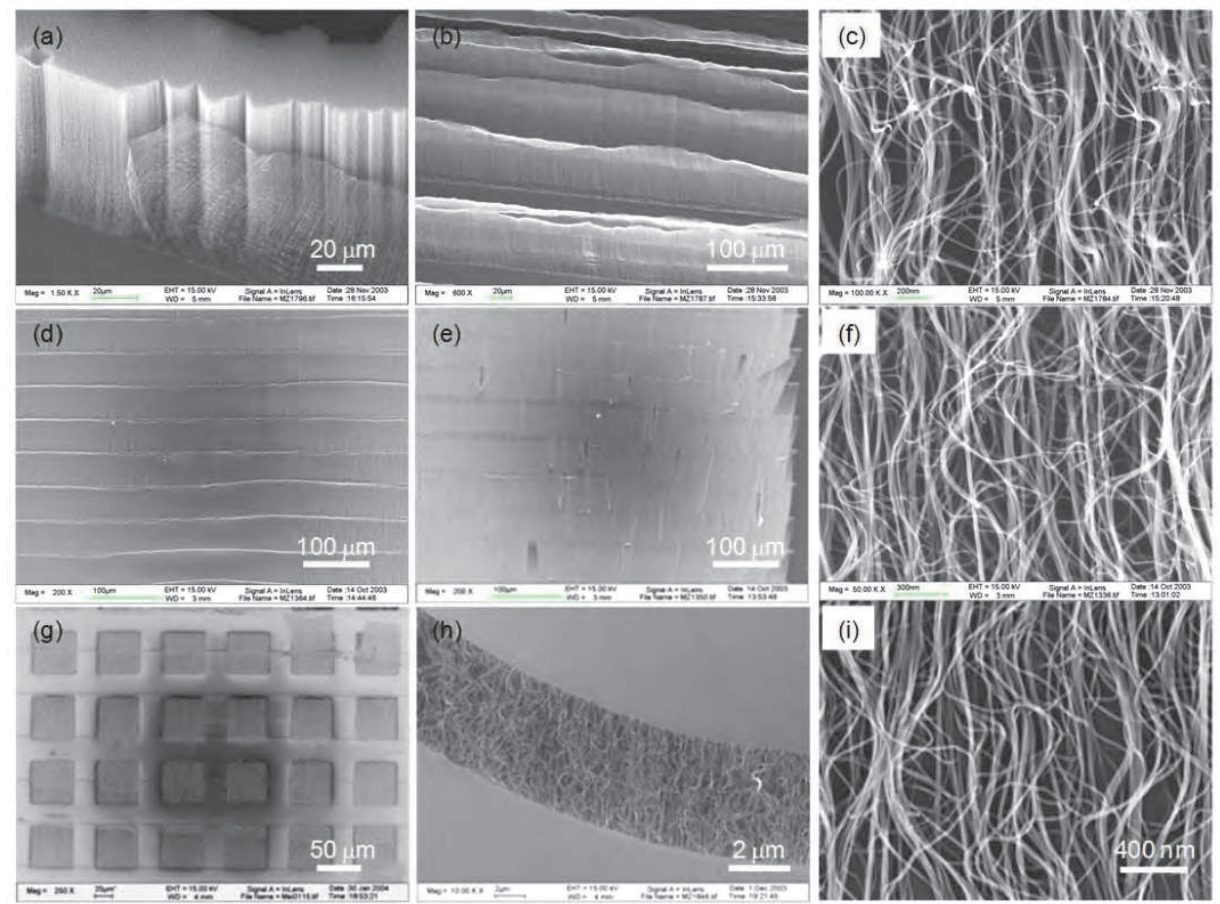

Fig. 2. SEM images show CNTs grown perpendicular to a substrate as a forest and a thin wall (a) and a thin wall array (b). (c) SEM image in high magnification shows the structure of the thin wall. The wall is so thin, it is transparent. (d), (e), and (f) show the thin wall array is "knocked" down and CNTs forms an aligned thin film on substrate. $(\mathrm{g})$ and $(\mathrm{h})$ show that the CNT thin films are etched into desired patterns. After removal of the photo resist, the CNTs have clean surface and keep the original structures. (f) and (i) show the detail of (e) and $(\mathrm{h})$, respectively. The dark circle in (d), (e), and (g) is the shadow of the in-lens detector. 
drawn through an acetone solution to horizontally redirect the vertical alignment and dried using nitrogen gas (Fig. $1 \mathrm{~b}$ and Figs. $2 \mathrm{~d}$ to $2 \mathrm{f}$ ). The width of the patterned catalyst lines and the growth time of CVD determined the thickness and the height of the CNT walls. The walls do not shrink in height during flattening and drying. Figure 2e shows that a CNT sheet on substrate is formed from the CNT wall array in which the height of the wall is controlled to just 2 times the gap between two catalyst lines so that the CNT sheet on substrate has the thickness of two overlapping walls. The thickness of the CNT sheet could range from a few hundred nanometers to micrometers through the same process by using forest of different thicknesses, namely by controlling the width of the catalyst lines. Substrate-forest interaction and lateral CNT orientation guided densification only in wall thickness direction to essentially flatten the walls to the substrate with strong adhesion. It is because of the surface tension of the liquids and the strong van der Waals interactions that effectively close the CNTs together when liquids were introduced into the thin forest and dried. This self-assembly transformed CNT walls into highly densely packed CNT thin sheets. The CNT sheet was patterned into arbitrarily shaped CNT islands in desired positions by using standard lithographic processes. Figures $2 \mathrm{~g}$ and $2 \mathrm{~h}$ are the SEM images showing the patterned CNT sheet by lithography process. The CNT sheets were etched vertically by oxygen/argon reactive ion etching by using a resist as a mask. Figure $2 \mathrm{i}$ is the SEM image of Fig. $2 \mathrm{~h}$ in high magnification. The surface of the CNTs is clean and the structures of the sheet remain the same, showing that the adhesion with the substrate is sufficient to withstand lithographic processes including heat treatment, immersion into liquids, and drying. The bright and parallel horizontal lines visible in the images are catalyst lines. These lines cannot be totally removed (Fig. 2g). The sheet has to be transferred to another substrate in order for the effects of these lines to be negligible for some applications.

\subsection{Drawing approach}

In drawing approach, the catalyst thin film covers all surface of the Si substrate (Fig. 3). The CNTs are synthesized on top of silicon substrate as a vertically aligned forest by CVD and the transparent nanotube sheets were drawn directly from CNT forests. Draw was initiated using an adhesive strip, like that on a $3 \mathrm{M}$ Post-it ${ }^{\circledR}$ Note, or using a blade by cutting into the forest to contact CNTs teased from the forest sidewall. Five-centimeter wide, meter long transparent sheets were made at a meter per minute by hand drawing (M. Zhang et al., 2005).

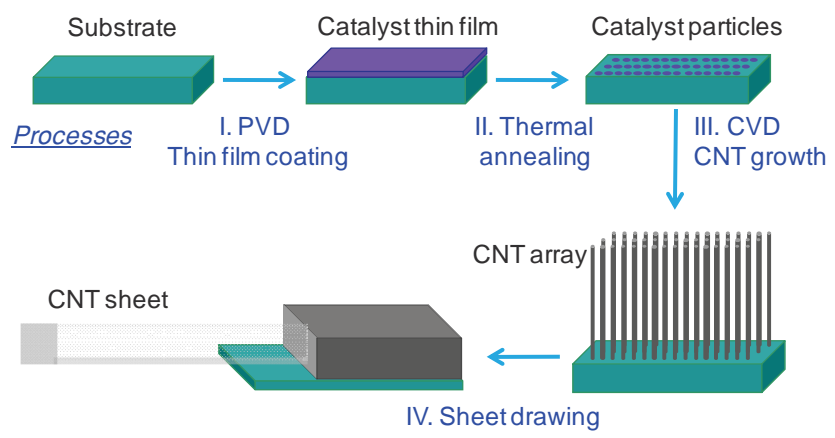

Fig. 3. Schematic experimental processes for fabrication of the free-standing CNT sheet. 
Despite a measured areal density of only $\sim 3 \mu \mathrm{g} / \mathrm{cm}^{2}$, these $500 \mathrm{~cm}^{2}$ sheets were selfsupporting during drawing. Figure 4 shows side-view and top view SEM micrographs of forest and sheet. It indicates that the nanotubes in the forest transition from the highly ordered forest state to a rather disordered intermediate state immediately in front of the forest sidewall, and finally to the highly oriented aerogel state. By taking sequential micrographs through a SEM to form a movie, the process in which the forest nanotubes rotate by about $90^{\circ}$ in going from nanotube orientation in the forest to that of the highly oriented state is captured (Kuznetsov et al., 2011).
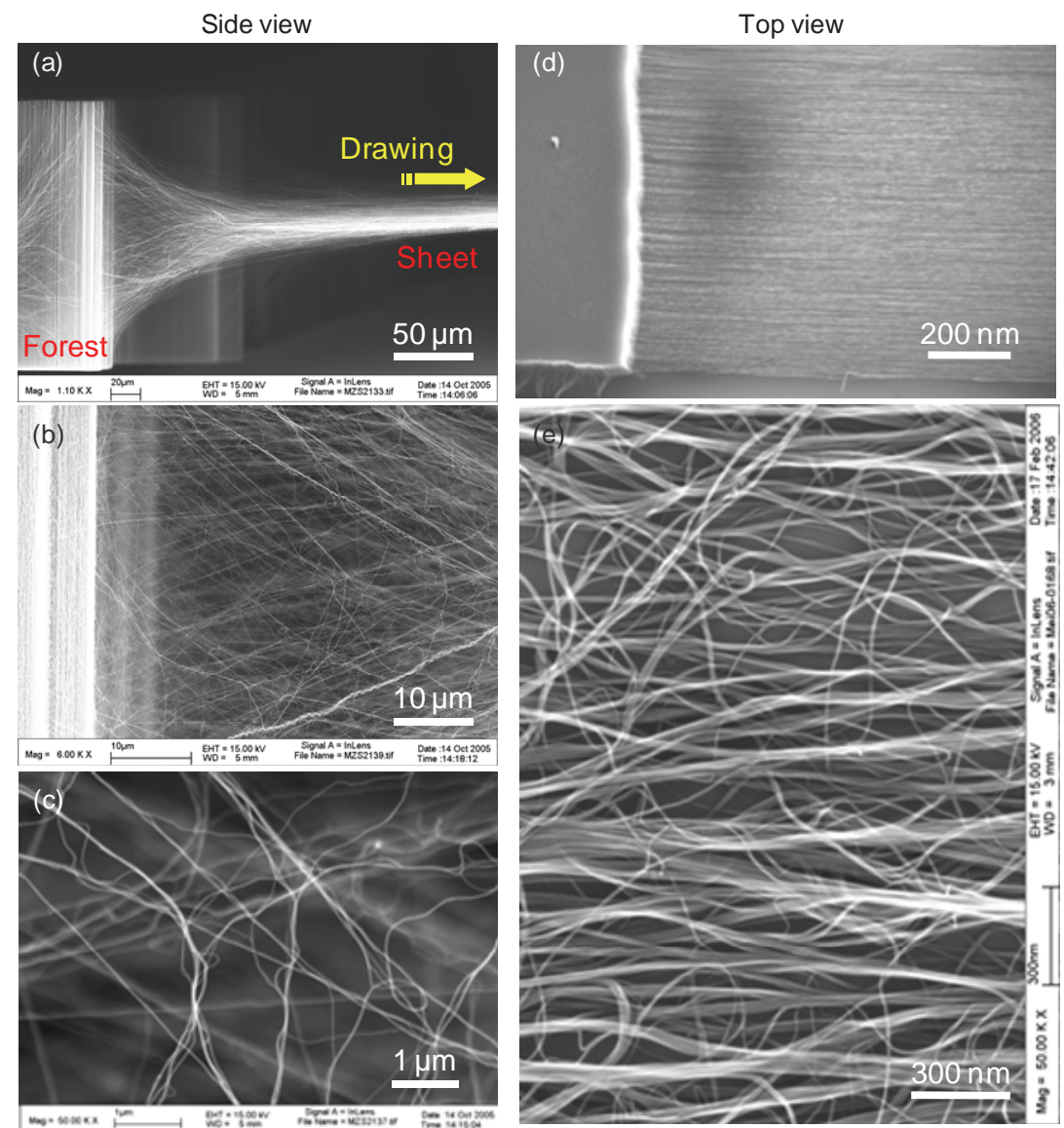

Fig. 4. SEM images show that a CNT sheet is drawing from a forest. (a)-(c) Side view of the forest and the sheet close to the forest. (b) and (c) show the details in (a) and (b), respectively. (d) and (e) Top view of the forest and the CNT sheet.

The forest-drawn CNT sheets can easily be stacked or conveniently assembled into biaxially reinforced sheet arrays. They can be used as conducting layers on non-planar surfaces (Figs. $5 \mathrm{a}$ to $5 \mathrm{~d}$ ). These highly anisotropic aerogel sheets can be applied and easily densified into highly oriented sheets having a thickness of $50 \mathrm{~nm}$ and a density of $\sim 0.5 \mathrm{~g} / \mathrm{cm}^{3}$. We obtain 

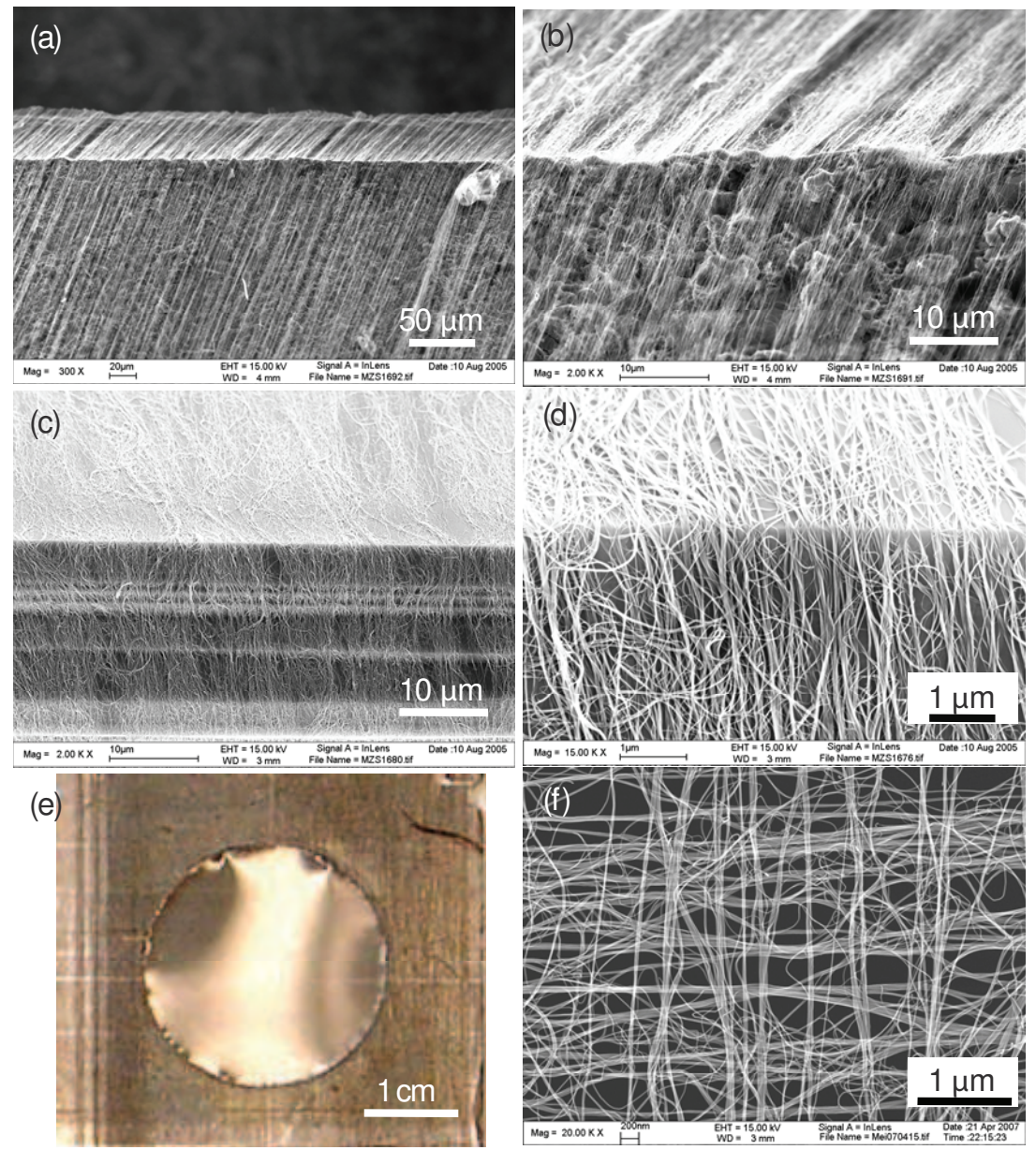

Fig. 5. (a)-(d) SEM images show a CNT sheet covers a substrate with sharp turns. (b) and (d) are the SEM images in higher magnification of the images in (a) and (c), respectively. (e) A photo image shows cross stacked sheets cover a metal plane with a $2.5 \mathrm{~cm}$-diameter hole after liquid densification. The detail structure is shown in (f).

this 360 -fold density increase by simply adhering by contact the as-produced sheet to a planar substrate (e.g. glass, many plastics, silicon, gold, copper, aluminum, and steel), vertically immersing the substrate with attached CNT sheet into a liquid (e.g. ethanol) along the nanotube alignment direction, and retracting the substrate from the liquid. Surface tension effects during ethanol evaporation shrink the aerogel sheet thickness to $\sim 50 \mathrm{~nm}$. SEM micrographs taken normal to the sheet plane suggest a decrease in nanotube orientation as a result of densification (Fig. 4e). This observation is deceptive - the collapse of $\sim 20 \mu \mathrm{m}$ sheets to $\sim 50 \mathrm{~nm}$ sheets without changes in lateral sheet dimensions means that out-of-plane deviations in nanotube orientation become in-plane deviations that are noticeable in the SEM micrographs. The aerogel sheets can be effectively glued to a substrate 
by contacting selected regions with ethanol, and allowing evaporation to densify the aerogel sheet. Adhesion increases because the collapse of aerogel thickness increases contact area between the nanotubes and the substrate.

The aerogel sheets can also be densified into super-thin and free-standing sheet. Figure $5 \mathrm{e}$ is a photo image showing that a densified CNT sheet covers a $2.5 \mathrm{~cm}$ diameter hole in a metal plane. The super-thin sheet is made by densifing two cross-stacked CNT sheets (Fig. 5f). The nanotube sheets, which combine high transparency with high electronic conductivity, are highly flexible and provide giant gravimetric surface areas. The measured gravimetric strength of orthogonally oriented sheet arrays exceeds that of a high-strength steel sheet (Alive et al., 2009; M. Zhang et al., 2005). These sheets have been used in laboratory demonstrations for microwave bonding of plastics and for making transparent, highly elastomeric electrodes; planar sources of polarized broad-band radiation; conducting appliqués; flexible organic light-emitting diodes; and solar cells (Alive et al., 2009; Ulbricht et al., 2006 \& 2007; Williams et al., 2008; M. Zhang et al., 2005).

Many real applications, such as field and thermionic emission electron sources (Kuznetzov et al., 2010; P. Liu et al., 2010; Y. Wei et al., 2008; Xiao et al., 2008; Y. C. Yang et al., 2010), loudspeakers (Alive et al., 2010; Kozlov et al., 2009; Xiao et al., 2008), CNT touch screens (Feng et al., 2010), high strength CNT yarns (Lima et al., 2011; K. Liu et al., 2010; M. Zhang et al., 2004; X. Zhang et al., 2006; Zhong et al., 2010), electrodes for batteries and supercapacitors (H. X. Zhang et al., 2009; R. F. Zhou et al., 2010), CNT/polymer composites (Q. F. Cheng et al., 2010; L. Chen et al., 2009; M. Zhang et al., 2005), and wrappers (Lima et al., 2011) were demonstrated. It is also demonstrated that the CNT sheets can be used as scaffolds for tissue engineering (Galvan-Garcia et al., 2007). It is no doubt that more applications will be developed and practiced.

\section{Making drawable CNT forest}

The CNT draw process does not work for all CNT forests. The experimental results show that the drawability depends strongly on the structural interconnections between CNTs and the network of interconnections between CNT bundles within the forest. The nanotubes in the forest should be intermittently bundled in order to be drawable (Fig. 6). In the forest height direction, this means that a nanotube switches many times from being bundled with a few neighboring nanotubes, to being unbundled, and then to being bundled with a few different neighboring nanotubes. Bundled nanotubes are simultaneously pulled from different elevations in the forest sidewall so that they join with bundled nanotubes that have reached the top and bottom of the forest, thereby minimizing breaks in the resulting fibrils (containing many bundled CNTs) (Figs. $4 \mathrm{~b}$ and $4 \mathrm{c}$ ). If there is too little lateral connectivity in the forest, the forest is undrawable because pulling on the forest sidewall just removes a few nanotubes rather than a continuous sheet. If there is too much inter-tube connectivity, only a chunk of forest is extracted before draw terminates.

The interconnections between CNTs and CNT bundles are formed during CNT growth, which are determined by the synthesis process. The CNT synthesis process is a complex process, which is related to the substrate and supporting materials, catalyst materials and their amount, carbon sources and partial pressure (feedstock), carrier gas and gas as an etching agent, total flow rate (gas residual time), process temperature, temperature ramp-up rate and cool-down rate, process pressure, process steps, process time, and many other 
details, such as history of reaction chamber, contamination, size of chamber and substrate, etc. CNT forests can be produced over a broad range of conditions. However, not every forest is suitable for solid-state fabrication of CNT sheets. This is because the forest needs to meet certain conditions to be a drawable CNT forest as described above. The drawable forest can be fabricated by just using $\mathrm{C}_{2} \mathrm{H}_{2} / \mathrm{Ar}$ (without $\mathrm{H}_{2}$, water or other agents) and $\mathrm{Fe}$ thin film on $\mathrm{Si}$ substrate (without buffer layers such as $\mathrm{SiO}_{2}$ and $\mathrm{Al}_{2} \mathrm{O}_{3}$ ). The buffer layers and other gases as well as their combinations are necessary to control the size and properties of CNTs. The drawable forests can be fabricated under different synthesis conditions. The CNT area density, height of forest, and purity of the CNTs are considered being the parameters for monitoring and controling the interconnections of CNTs in the forest.

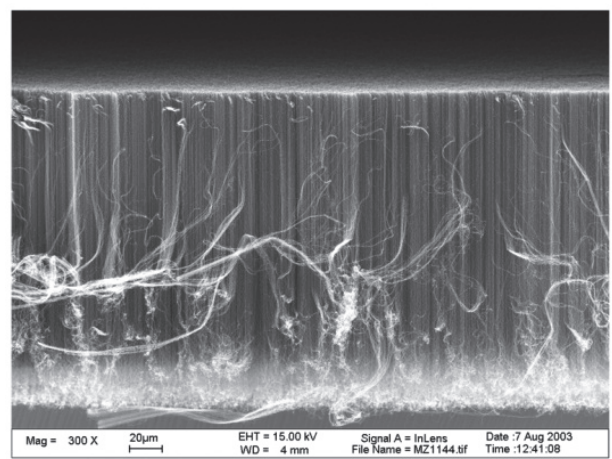

(a)

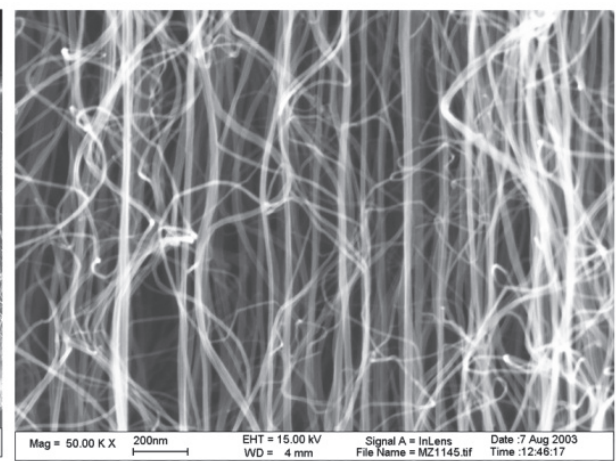

(b)

Fig. 6. SEM images show the side views of a drawable CNT forest (a) and its structure in high magnification (b).

\subsection{Structures of CNT forest}

A single nanotube naturally curves (in bending status) during growth if no external forces exist. The bending stress can come from the nanotube's own weight, interaction with neighbor nanotubes, or limited growing space. As shown in Fig. 7a, a single tube keeps growing straight for a limited length: it falls down to the substrate and turns its growth direction many times during CVD process. A group of CNTs can form a randomly oriented CNT mat or well-aligned CNT arrays, depending on the density of catalyst and their activities under the same synthesis conditions. Figures $7 \mathrm{~b}$ to $7 \mathrm{~d}$ show the effects of the number of catalyst particles with similar area density on the formation of a CNT thin sheets array. Figure $7 \mathrm{~b}$ shows CNT walls that were grown from $0.1 \mu \mathrm{m}$ wide and $40 \mu \mathrm{m}$ long catalyst lines patterned by e-beam lithography. There were no external forces during CNT growth. The walls bend when their height is over a certain level. The bending directions and angles depend on each wall's morphologies. The nanotubes within each wall confine the nearest neighbors and attract the outermost nanotubes to their neighbors via van der Waals forces, thereby producing oriented growth. However, the CNTs in such thin walls present random curvatures and are tangled (Fig. $7 \mathrm{~b}$ ) because of the weak confinement in thickness direction. As the thickness of the wall increases, the alignment of the CNTs is improved due to the crowding effect. Figure 7c shows $\sim 100 \mu \mathrm{m}$ high CNT wall array grown from a $0.5 \mu \mathrm{m}$ 
wide and $40 \mu \mathrm{m}$ long catalyst lines in which nanotubes were better aligned (Fig. $7 \mathrm{~d}$ ). In a forest, the CNTs can have different growth rates, which lead to the structure of the forest. Figure 8 shows three typical structures. In Fig. $8 \mathrm{f}$, more than $80 \%$ of the CNTs are not straight: they periodically bend within fixed intervals throughout their entire length. As a result of this regular bending, a wavy structure resulted. It is believed that the wavy structure is formed because there are roughly two groups of catalysts uniformly distributed on substrate: one is more active and results in higher CNT growth rate than the other. Due to van der Waals forces, which stick nanotubes together whenever they touch, the growth rate of the array is limited by the nanotubes with relatively slow growth rate when catalysts stay on the surface of substrate. The nanotubes with higher growth rate are forced to bend periodically. The period of the wave is related to the ratio of growth rates of these two groups (Fig. 8c). When the distribution of the catalyst activity is relatively narrow and the density is high (Fig. 8a), the forest will have the morphology as shown in Fig. 8d. When the distribution of the catalyst activity results in the distribution of growth rate as shown in Fig. $8 \mathrm{~b}$ and the density is high, the forest will be formed by the straight CNTs which form bundles while the waved CNTs switch between different bundles as the morphologies show in Figs. $6 \mathrm{~b}$ and 8e. Such structure is believed to be important for assembling CNT sheets by drawing CNTs directly from the forest.

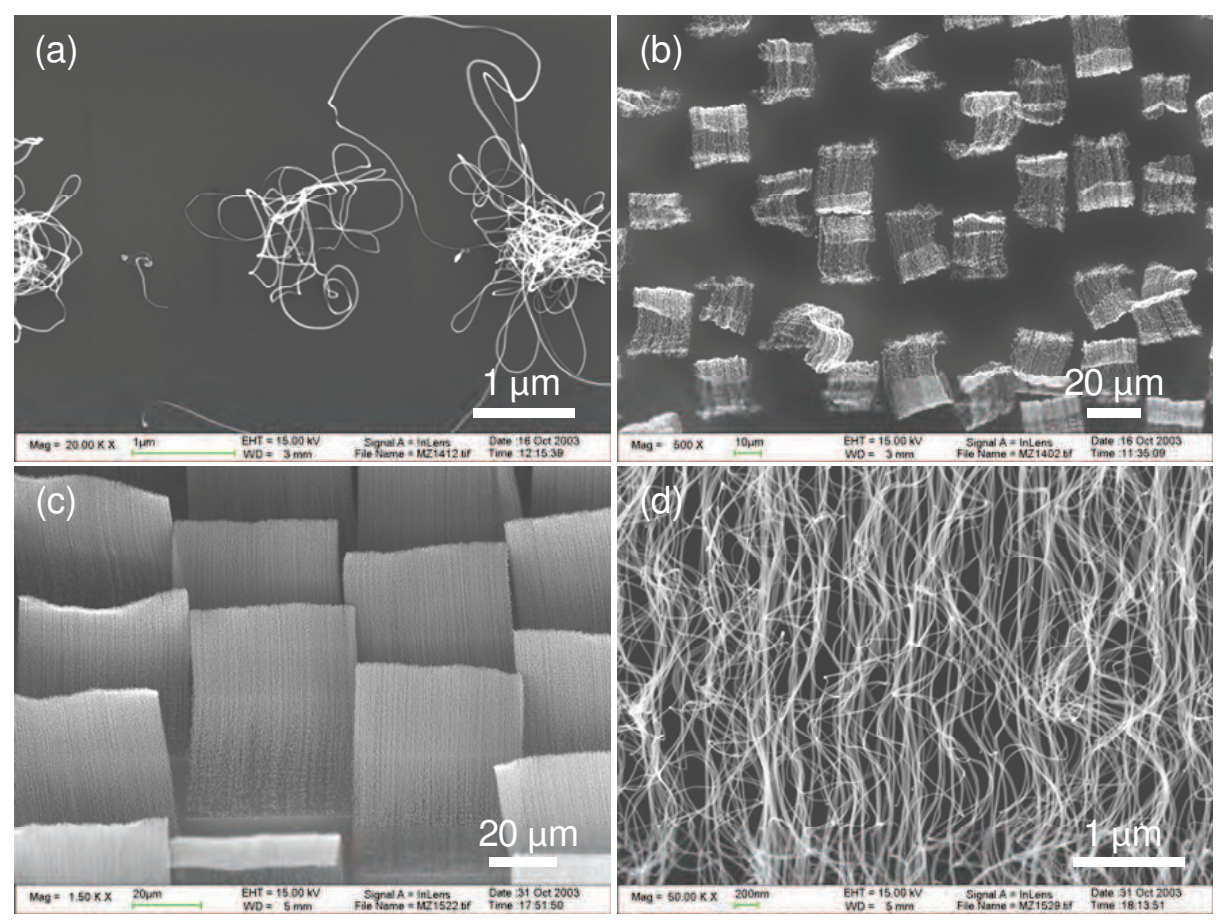

Fig. 7. SEM image of CVT walls grow on patterned (a) very thin, (b) $0.1 \mu \mathrm{m}$ wide and $40 \mu \mathrm{m}$ long, and (c) $0.5 \mu \mathrm{m}$ wide and $40 \mu \mathrm{m}$ long catalyst lines. (d) SEM image of the CNTs in a wall in (c). 

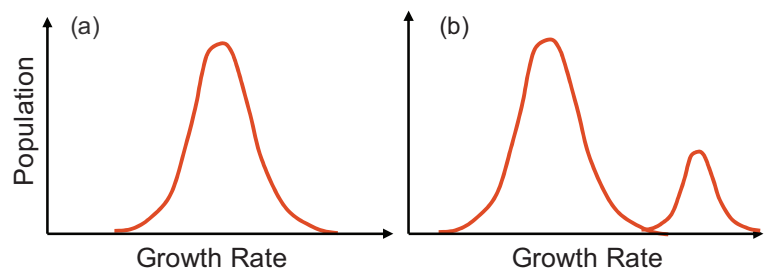

Growth Rate
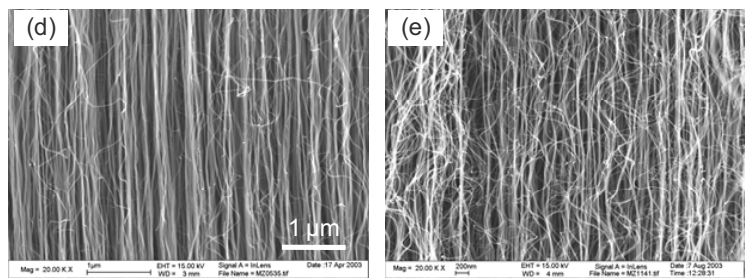

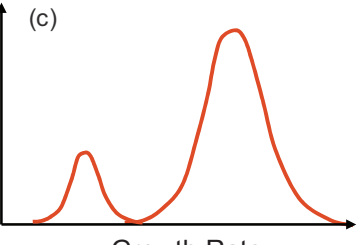

Growth Rate

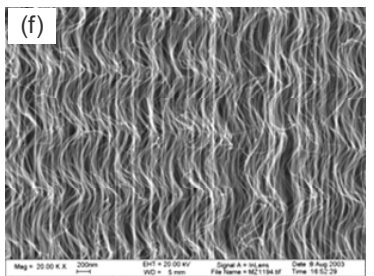

Fig. 8. (a) to (c) Schematic of the population of the CNTs related with the growth rate and (d) to (f) typical SEM images of the CNT forests. (d), (e), and (f) are in the same scale and they are corresponding to (a), (b), and (c), respectively.

\subsection{CNT area density}

As shown in Fig. 7, CNT area density (number of nanotubes per square centimeter) in the forest is a key factor to establishing the interconnections between CNTs in the forest and the drawability of the forest. The schematic illustration of drawability to the area density is shown in Fig. 9. If the area density is very low, CNTs will lay on the substrate randomly. The CNTs can grow in the out-of-plane direction and form a vertical aligned forest when its area density exceeds a threshold value. If the forest has very high density, the CNTs in the forest will form big bundles and the forest will not be drawable.

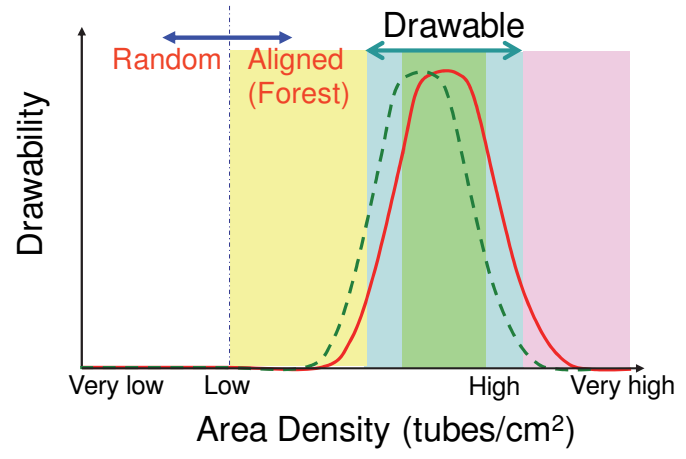

Fig. 9. Schematic illustration showing the relationship between the forest drawability and the area density of CNTs. The dash line corresponds to the forest with higher height.

Experimentally, the area density of the forest is calculated from counting the root of the nanotubes on substrate after removal the forest from the substrate. Figure 10 shows the surfaces of the substrates after removing the forest. Each circle dot in the images is the root of a nanotube. 


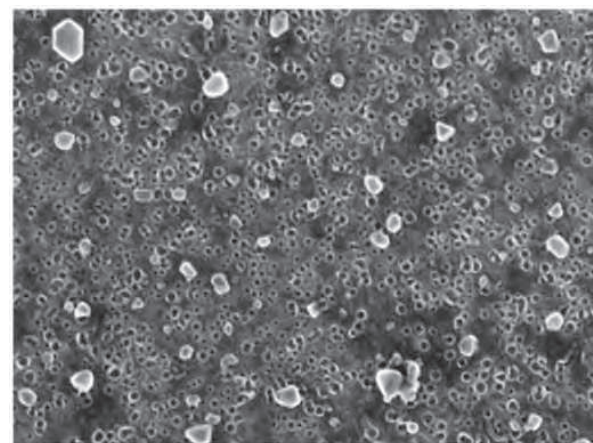

(a)

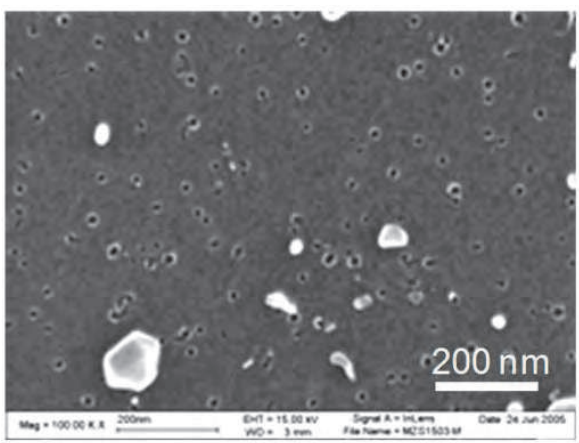

(b)

Fig. 10. SEM images show the surfaces of the substrate after removal CNT forests. (a) and (b) show the typical surfaces of the drawable forest and the un-drawable forest, respectively. Each circle in the image is a root of a CNT. The bright dots are the by-products of the CVD process. Two images are in the same scale.

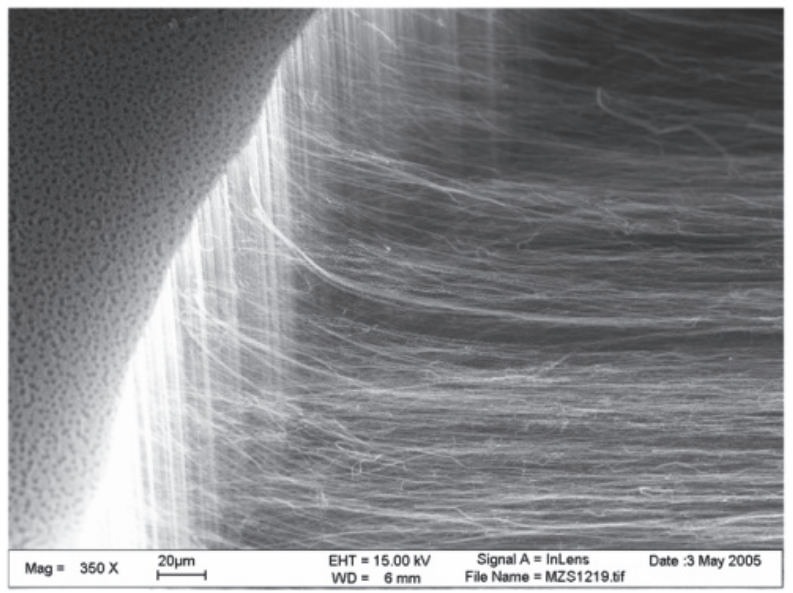

Fig. 11. SEM image of a drawable forest. There are holes with $\sim 1 \mu \mathrm{m}$ diameter distributed in the forest.

Drawable forests must have a high enough area density for CNTs in the forest to form interconnections. The required area density of the forest is related to the diameter of the nanotubes. When the forest is formed by CNTs with $\sim 10 \mathrm{~nm}$ diameters, the well-drawn forest has the area density $\sim 1011 / \mathrm{cm}^{2}$, and the undrawable forest has an area density of less than $10^{10} / \mathrm{cm}^{2}$. The area density needs to be higher for the forest with thinner CNTs.

The effect of area density can be compensated by adjusting the height of the forest (see section 3.4). The area density can also be lowered by controlling the distribution of catalysts through patterning. Figure 11 shows the SEM image of a drawable forest. There are uniformly distributed holes due to the missing catalysts on the substrate. The less CNT interconnections in the holes results in the easy draw of the too densely packed CNT forest. 


\subsection{Purity of the CNTs}

Generally, the drawable forests need to be clean. Amorphous carbon (a-C) deposited on CNTs during CVD process might not be avoidable. A proper amount a-C might be helpful in CNT interconnections. However, too much a-C will increase the locking between CNTs and CNT bundles, which will cause the breaking of fibrils during sheet draw. The results of TGA measurement of the drawable forest and TEM observation of the CNT sheet are shown in Fig. 12.

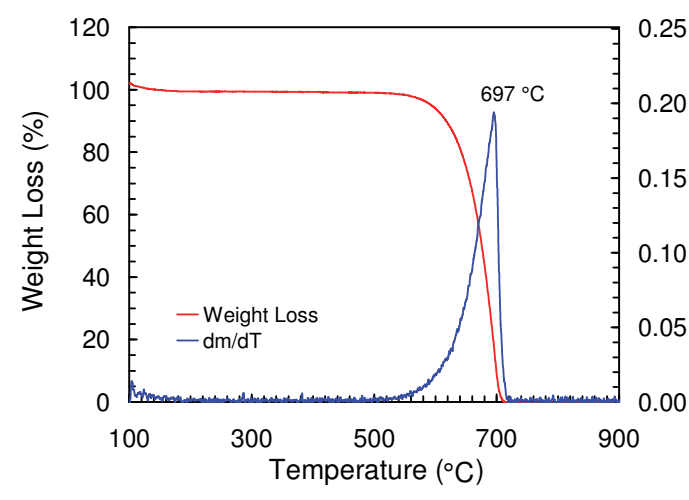

(a)

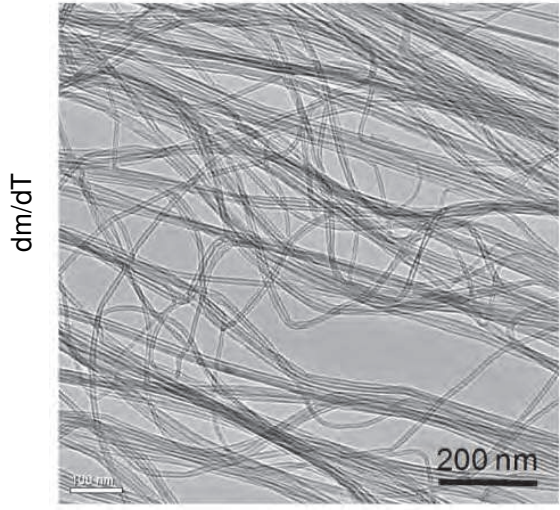

(b)

Fig. 12. (a) TGA data shows the thermal stability and the purity of the CNTs and (b) TEM image of a CNT sheet.

\subsection{Height of the forest}

As described above, the interconnections of CNTs in the forest play an important role in the drawability of the forest. The CNTs form small bundles, each consisting of a few nanotubes, in the forest with individual nanotubes moving in and out of different bundles. The threedimensional connectivity caused by intermittently switched bundling is believed to be important for the drawing process. The too-long and too-short CNT forests are not suitable for the solid-state process because the interconnections there either too much or too little for continuously pulling CNTs out of the forest. Figure 13a is the schematic relationship between drawability and length of the forest. CNTs can be drawn from a $\sim 20 \mu \mathrm{m}$ high forest as shown in Fig. 13b. Experiments demonstrated that the good drawablity has been obtained in up to $500 \mu \mathrm{m}$ high forests formed by nanotubes $\sim 10 \mathrm{~nm}$ in diameter. Two-millimeter high forests formed by tubes $30 \sim 50 \mathrm{~nm}$ in diameter are demonstrated to be drawable Inoue, 2011.

Since the drawability is determined by the interconnections of CNTs in the forest, the veryshort and very-high forests could be drawable by adjusting other parameters. For example, very-short forest could be drawable if the area density is high enough and relatively more interconnections occur along their length. For high forests, lowering the area density and the interconnections between CNTs and their bundles along their length will create the same effect (Fig. 9). 


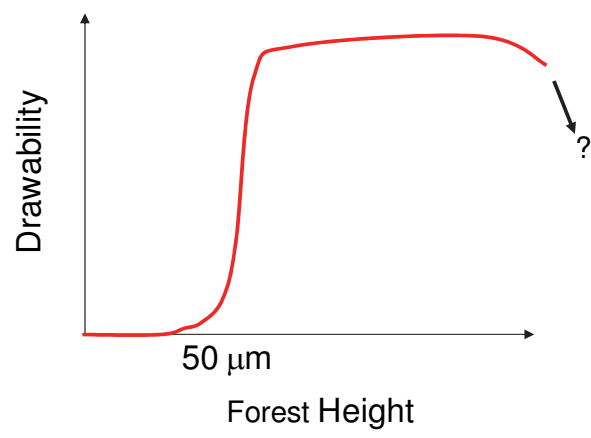

(a)

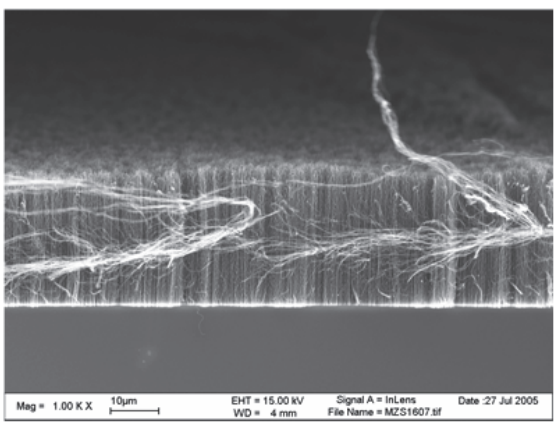

(b)

Fig. 13. (a) Schematic of the possible relationship between drawability and forest height. (b) SEM image shows that the CNTs can be drawn continuously from a $20 \mu \mathrm{m}$ high CNT forest.

The forest-sheet conversion rate and the thickness of as-produced sheet depend on the height and the density of the forest, as well as the bundling level of tubes in the forest. For forests having similar topology, the highest forests were easiest to draw into sheets - most probably because increasing nanotube length increases inter-fibril mechanical coupling within the sheets, and produce a higher forest-sheet conversion rate. A one centimeter length of $245 \mu \mathrm{m}$ high forest converts to about a three-meter-long free-standing CNT sheet. By adjusting the height and density of the forest; converting a one centimeter length forest to over a ten meter long sheet has been achieved. The thickness of the as-produced CNT sheet increased with increasing forest height and was $\sim 18 \mu \mathrm{m}$ in SEM images of a sheet drawn from a $245 \mu \mathrm{m}$ high forest.

\subsection{Process temperature}

Temperature is another important parameter, which determines other synthesis parameters for CNT growth and the quality of the CNTs. The intensity ratio of the $\mathrm{G}$ band ( $\mathrm{I}_{\mathrm{G}}$ at $\sim 1580$ $\left.\mathrm{cm}^{-1}\right)$ and $\mathrm{D}$ band $\left(\mathrm{I}_{\mathrm{D}}\right.$ at $\left.\sim 1350 \mathrm{~cm}^{-1}\right)$ in Raman spectra and the initial burning temperature of the CNTs obtained from the TGA are used to evaluate the quality of the CNTs. G band and $\mathrm{D}$ band were originated from the Raman active in-plane atomic displacement $\mathrm{E}_{2 \mathrm{~g}}$ mode and disorder-included features due to the finite particle size effect or lattice distortion, respectively (Tuinstra \& Koenig, 1970). The increase of $I_{G} / I_{D}$ indicates that the degree of long-range ordered crystalline perfection of the CNTs increases. The better the crystallization of the graphene layers of the CNTs, the higher the initial burning temperature of the CNTs. Maintaining a spatial homogeneous temperature during the growth process was demonstrated a critical factor for fabricating long CNTs with consistent electrical characteristics (X. Wang et al., 2009). Many researches show that the quality of the CNTs becomes better as the growth temperature increases (Y. T. Lee et al., 2002; C. J. Lee et al., 2001; K. Kim et al., 2005; X. Feng et al., 2009). However, other parameters for CNT growth must be optimized if increasing temperature since the temperature increase has direct influences on the formation and the activity of the catalysts and the feedstock of the carbon atoms. The partial pressure of the hydrocarbon gas usually needs to be lowered at a higher process temperature. 


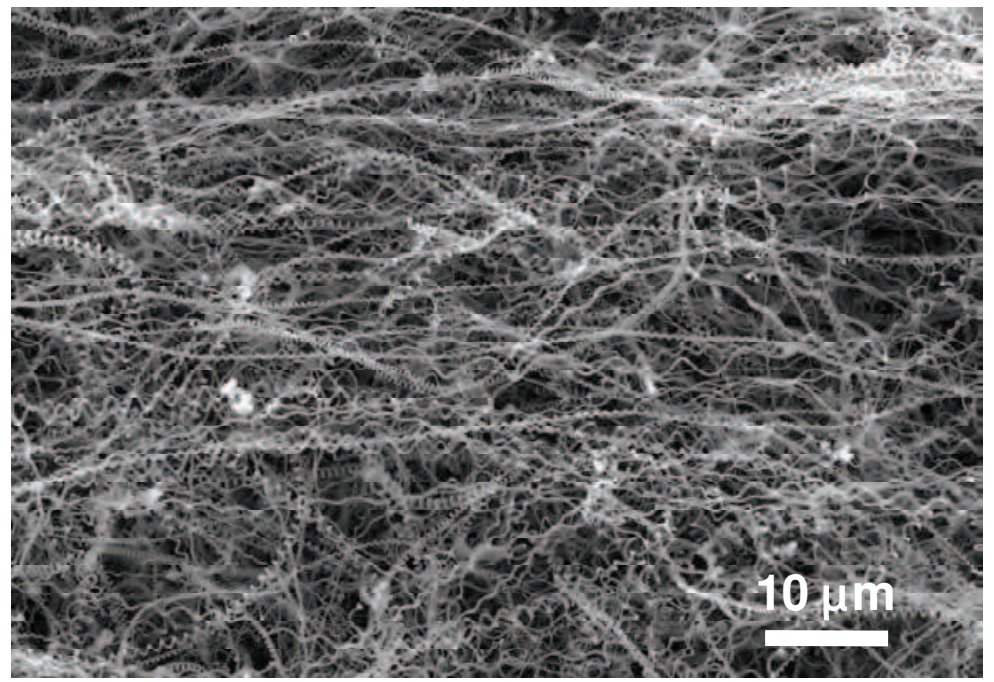

Fig. 14. SEM image of large amount of helically coiled carbon nanostructures. Each coil grows with its own diameter and pitch.

\section{Conclusion}

Individual carbon nanotubes are like minute bits of string, and many trillions of these invisible strings must be assembled together to make useful macroscopic articles. This chapter presents the fabrication processes to making CNT sheets. The purity of the nanotubes, the height of the forest, the morphology of the forest, especially the 3D structure by self-assembly during CVD process, and the area density of the nanotubes are the main factors of the drawability of the forest. There are no inherent limitations on either sheet width or length, and no special difficulties arise in maintaining sheet quality during the draw. Currently, the sheets are drawn at up to $2 \mathrm{~m} / \mathrm{s}$ from special CNT forests (Alive et al., 2009; Lima, et al., 2011) and the width at up to $20 \mathrm{~cm}$ (C. Feng et al., 2010). This solid-state process is scalable for continuous, high-rate production. Extension of the technologies of solid-state sheet fabrication to longer CNTs, as well as to a few walled or single walled nanotubes, are important because longer nanotube lengths will enable properties improvements for active devices by means of enabling closer approach of sheet properties to those of individual nanotubes and the conductivity, transparency, and strength of the sheet could be improved by using thinner nanotubes.

CNTs can also be in the coiled structure (Amelinckx et al., 1994 ; Dunlap, 1992; M. Zhang \& J. Li, 2009). Figure 14 shows the helically coiled CNTs grown on iron-coated indium tin oxide substrate by catalytic CVD (M. Zhang et al., 2000). More than $95 \%$ of the wires are in helical structures. The coils have various diameters and pitches. They grow out of the substrate and maintain their self-organization well during growth. If the coiled CNT forest is drawable, the sheet will have interesting properties that the straight CNTs could not provide. There is plenty of room to further improve the processes and properties of the CNT sheets. 


\section{Acknowledgment}

This work was supported or supported partly by National Science Foundation, the Air Force Research Laboratory, Texas Advanced Technology Program, Robert A. Welch Foundation, and the Strategic Partnership for Research in Nanotechnology Consortium in Texas.

\section{References}

Ago, H.; Petritsch, K.; Shaffer, M. S. P.; Windle, A. H.; \& Friend, R. H. (1999). Composites of carbon nanotubes and conjugated polymers for photovoltaic devices. Adv. Matls. Vol. 11, pp. 1281-1285.

Amelinckx, S.; Zhang, X. B. ; Bernaerts, D.; Zhang, X. F. ; Ivanov, V. ; \& Nagy, J. B. (1994). A Formation Mechanism for Catalytically Grown Helix-Shaped Graphite Nanotubes. Science, Vol. 29, pp. 635-639.

Alive, A.; Lima, M. D.; Fang, S. \& Baughman R. H. (2010). Underwater sound generation using carbon nanotube projectors. Nano Lett., Vol. 10, No. 7, pp. 2374-2380.

Aliev, A. E.; Oh, J.; Kozlov, M. E.; Kuznetsov, A. A.; Fang, S. L.; Fonseca, A. F.; Ovalle, R.; Lima, M. D.; Haque, M. H.; Gartstein, Y. N.; Zhang, M.; Zakhidov, \& Baughman, R. H. (2009). Giant-Stroke, Superelastic Carbon Nanotube Aerogel Muscles. Science, Vol. 323, pp. 1575-1579.

Bachtold, A.; Hadley, P.; Nakanishi, T.; \& Dekker,C. (2001). Logic Circuits with Carbon Nanotube Transistors. Science, Vol. 294, pp. 1317-1320.

Berhan, L.; Yi, Y. B.; Sastry, A. M.; Munoz, E.; Selvidge, M.; \& Baughman, R. (2004). Mechanical properties of nanotube sheets: Alterations in joint morphology and achievable moduli in manufacturable materials. J. Appl. Phys. Vol. 95, pp. 43354346.

Chen, L.; Liu C.; Wang, J.; Zhang, W.; Hu, C.; \& Fan, S. (2009). Auxetic Materials with Large Negative Poisson's Ratios Based on Highly Orientied Carbn Nanotube Structures. Appl. Phys. Lett. Vol. 94, pp. 253111.

Cheng, Q.F.; Wang, J.P.; Wen, J.J.; Liu, C.H.; Jiang, K.L.; Li, Q.Q.; \& Fan, S.S. (2010). Carbon nanotube/epoxy composites fabricated by resin transfer molding. Carbon, Vol. 48, pp. 260-266.

Dan, B. ; Irvin, G. C. ; \& Pasquali, M. (2009). Continuous and Scalable Fabrication of Transparent Conducting Carbon Nanotube Films. ACS nano, Vol. 3, No. 4, pp. 835843.

Dunlap, B. I. (1992). Connecting carbon tubules. Phys. Rev. B, Vol. 46, pp. 1933-1936.

Endo, M.; Muramatsu, H.; Hayashi, T.; Kim, Y. A.; Terrones, M.; \& Dresselhaus, M. S. (2005). Nanotechnology: 'Buckypaper' from coaxial nanotubes. Nature, Vol. 433, p. 476.

Feng, X.; Liu, K.; Xie, X.; Zhou, R.; Zhang, L.; Li, Q.; Fan, S.; \& Jiang, K. (2009). Thermal Analysis Study of the Growth Kinetics of Carbon Nanotubes and Epitaxial Graphene layers on Them. J. Phys. Chem. Vol. 113, PP. 9623-9631.

Feng, C.; Liu, K.; Wu, J.; Liu, L.; Cheng, J.; Zhang, Y.; Sun, Y.; Li, Q.; Fan, S.; Jiang, K. (2010). Flexible, stretchable, transparent conducting films made from superaligned carbon nanotubes. Adv. Funct. Mater. Vol. 20, pp. 885-891.

Fischer, J. E.; Zhou, W.; Vavro, J.; Llaguno, M. C.; Guthy, C.; Haggenmueller, R.; Casavant, M. J.; Walters, D. E.; \& Smalley, R. E. (2003). Magnetically aligned single wall 
carbon nanotube films: Preferred orientation and anisotropic transport properties. Journal of Applied Physics, Vol. 93, pp. 2157-2163.

Galvan-Garcia, P.; Keefer, E. W.; Yang, F.; Zhang, M.; Fang, S. L.; Zakhidov, A. A.; Baughman, R. H. \& Romero, M. I. (2007). Robust Cell Migration and Neuronal Growth on Pristine Carbon Nanotube Sheets and Yarns. Journal of Biomaterials Science, Vol. 18, pp. 1245-1261.

$\mathrm{Hu}$, L.; Hecht, D. S.; \& Gruener, G. (2010). Carbon Nanotube Thin Films: Fabrication, Properties, and Applications. Chem. Rev. Vol. 110, pp. 5790-5844.

Hu, L.; Hecht, D. S.; \& Gruener, G. (2004). Percolation in transparent and conducting carbon nanotube networks. Nano Letters, Vol. 4, pp. 2513-2517.

Inoue, Y.; Suzuki, Y.; Minami, Y.; Muramatsu, J.; Shimamura, Y.; Suzuki, K.; Ghemes, A.; Okada, M.; Sakakibara, S.; Mimura, H.; \& Naito K. (2011). Anisotropic Carbon Nanotube Papers Fabricated from Multiwalled Carbon Nanotubes Webs. Carbon, Vol. 49, pp. 2437-2443.

Ju, S. Y.; Facchetti, A.; Xuan, Y.; Liu, J.; Ishikawa, F.; Ye, P. D.; Zhou, C. W.; Marks, T. J.; Janes, D. B. (2007). Fabrication of Fully Transparent Nanowire Transistors for Transparent and Flexible Electronics. Nat. Nanotechnol., Vol. 2, pp. 378- 384.

Kim, K.; Kim, K. J.; Jung, W. S.; Bae, S. Y.; Park, J.; Choi, J.; \& Choo, J. (2005). Investigation on the temperature-dependent growth rate of carbon nanotubes using chemical vapor deposition of ferrocene and acetylene. Chemical Physics Letters, Vol. 401, pp. 459464.

Kim, Y.; Minami, N.; Zhu, W. H.; Kazaoui, S.; Azumi, R.; \& Matsumoto, M. (2003). Langmuir-Blodgett films of single-wall carbon nanotubes: layer-by-layer deposition and in-plane orientation of tubes. Jpn. J. Appl. Phys., Part 1, Vol. 42, pp. 7629-.

Kong, J. ; Soh, H. T. ; Cassell, A. M.; Quate, C. F.; \& Dai, H. (1998). Synthesis of individual single-walled carbon nanotubes on patterned silicon wafers. Nature, Vol. 395, pp. 878-881.

Kong, J.; Franklin, N. R.; Zhou, C.; Chapline, M. G.; Peng, S.; Cho, K.; \& Dai, H. (2000). Nanotube Molecular Wires as Chemical Sensors. Science, Vol. 287, pp. 622-625.

Kozlov, M. E.; Haines, C. S.; Oh, J.; Lima, M. D.; \& Fang, S. (2009). Sound of carbon nanotube assemblies. J. Appl. Phys., Vol. 106, pp. 124311.

Kuznetzov, A. A.; Lee, S. B.; Zhang, M.; Baughman, R. H.; \& Zakhidov, A. A. (2010). Electron field emission from transparent multiwalled carbon nanotube sheets for inverted field emission displays. Carbon, Vol. 48, pp. 41-46.

Kuznetsov, A. A.; Fonseca, A. F.; Baughman, R. H.; \& Zakhidov, A. A. (2011). Structural Model for Dry-Drawing of Sheets and Yarns from Carbon Nanotube Forests. ACS Nano, Vol. 5 (2), pp. 985-993.

Lee, C. J.; Park, J.; Huh, Y.; \& Lee, J. Y. (2001). Temperature effect on the growth of carbon nanotubes using thermal chemical vapor deposition. Chemical Physics Letters, Vol. 343, pp. 33-38.

Lee, Y. T.; Park, J.; Choi, Y. S.; Ryu, H. \& Lee, H. J. (2002). Temperature-Dependent Growth of Vertically Aligned Carbon Nanotubes in the Range $800-1100{ }^{\circ} \mathrm{C}$. J. Phys. Chem. B, Vol. 106, No. 31, pp 7614-7618.

Li, Y.; Kinloch, I. A.; \& Windle, A. H. (2004). Direct spinning of carbon nanotube fibers from chemical vapor deposition synthesis. Science, Vol. 304, pp. 276-278. 
Lima, D.; Fang, S.; Lepró, X.; Lewis, C.; Ovalle-Robles, R.; Carretero-González, J.; CastilloMartínez, E.; Kozlov, M. E.; Oh, J.; Rawat, N.; Haines, C. S.; Haque, M. H.; Aare, V.; Stoughton, S.; Zakhidov, A. A.; \& Baughman, R. H. (2011). Biscrolling Nanotube Sheets and Functional Guests into Yarns. Science Vol. 331, pp. 51-55.

Liu, K.; Sun, Y. H.; Zhou, R. F.; Zhu, H. Y.; Wang, J. P.; Liu, L.; Fan, S. S.; \& Jiang, K. L. (2010). Carbon Nanotube Yarns with High Tensile Strength Made by a Twisting and Shrinking Method. Nanotechnology, Vol. 21, pp. 045708.

Martin, C. (2010). A Carbon Nano-Wired World. R \& D magazine, Vol. 52, No. 3, June, 2010, p. 40.

Misewich, J. A.; Martel, R.; Avouris, Ph.; Tsang, J. C.; Heinze, S. \& Tersoff, J. (2003). Electrically Induced Optical Emission from a Carbon Nanotube FET. Science, Vol. 300, pp. 783-786.

Nanocomp Technologies Inc. (2011). http://www.nanocomptech.com/html/nanocomptechnology.html

Pevzner, A.; Engel, Y.; Elnathan, R.; Ducobni, T.; Ben-Ishai, M.; Reddy, K.; Shpaisman, N.; Tsukernik, A.; Oksman, M.; \& Patolsky, F. (2010). Knocking Down Highly-Ordered Large-Scale Nanowire Arrays. Nano Lett., Vol. 10, pp. 1202- 1208.

Rinzler, A. G.; Liu, J.; Dai, H.; Nikolaev, P.; Huffman, C.B.; Rodr'ı́1guez-Mac'1as, F.J.; Boul, P.J.; Lu, A.H.; Heymann, D.; Colbert, D.T.; Lee, R.S.; Fischer, J.E.; Rao, A.M.; Eklund, P.C.; \& Smalley, R.E. (1998). Large-scale purification of single-wall carbon nanotubes: process, product, and characterization. Applied Physics A, Vol. 67, pp. 29-37.

Sreekumar, T. V.; Liu, T.; Kumar, S.; Ericson, L. M.; Hauge, R. H.; \& Smalley, R. E. (2003). Single-wall carbon nanotube films. Chemistry of Materials, Vol. 15, pp. 175-178.

Tans, S. J.; Verschueren, A. R. M.; \& Dekker, C. (1998). Room-temperature transistor based on a single carbon nanotube. Nature, Vol. 393, pp. 49-52.

Ulbricht, R.; Lee, S. B.; Inoue, K.; Zhang, M.; Fang, S.; Baughman, R. H.; \& Zakhidov, A. A. (2007). Transparent Carbon Nanotube Sheets as 3-D Charge Collectors in Organic Solar Cells. Solar Energy Materials and Solar Cells, Vol. 91, pp. 416-419.

Ulbricht, R.; Jiang, X.; Lee, S. B.; Inoue, K.; Zhang, M.; Fang, S.; Baughman, R. H.; \& Zakhidov, A. A. (2006). Polymetric Solar Cells with Oriented and Strong Transparent Carbon Nanotube Anode. Phys. Stat. Sol. B, Vol. 243, pp. 3528-3532.

Unidym Inc. (2007). http:/ / www.unidym.com.

Wang, D.; Song, P.; Liu, C.; Wu, W.; \& Fan, S. (2008). Highly oriented carbon nanotube papers made of aligned carbon nanotubes. Nanotechnology, Vol. 7, pp. 075609.

Wang, X.; Li, Q.; Xie, J.; Jin, Zhong.; Wang, J.; Li, Y.; Jiang, K.; \& Fan, S. (2009). Fabrication of ultralong and electrically uniform single-walled carbon nanotube on clean substrates. Nano Lett. Vol. 9, No. 9, pp. 3137-3141.

Wei, Y.; Liu, L.; Liu, P.; Xiao, L.; Jiang, K.; \& Fan, S. (2008). Scaled fabrication of singlenanotube-tipped ends from carbon nanotube micro-yarns and their field emission applications. Nanotechnology, Vol. 19, pp. 475707.

Williams, C. D.; Robles, R. O.; Zhang, M.; Li, S.; Baughman, R. H.; \& Zakhidov, A. A. (2008). Multiwalled carbon nanotube sheets as transparent electrodes in high brightness organic light-emitting diodes. Applied Physics Letters, Vol. 93, pp. 183506. 
Wu, Z. C.; Chen, Z. H.; Du, X.; Logan, J. M.; Sippel, J.; Nikolou, M.; Kamaras, K.; Reynolds, J. R.; Tanner, D. B.; Hebard, A. F.; \& Rinzler, A. G. (2004). Transparent, conductive carbon nanotube films. Science, Vol. 305, pp. 1273-1276.

Xia, Y. N.; Yang, P. D.; Sun, Y. G.; Wu, Y. Y.; Mayers, B.; Gates, B.; Yin, Y. D.; Kim, F.; Yan, Y. Q. (2003). One-Dimensional Nanostructures: Synthesis, Characterization, and Applications. Adv. Mater. Vol. 15, pp. 353- 389.

Xiao, L.; Liu, P.; Liu, L.; Jiang, K.; Feng, X.; Wei, Y.; Qian, L.; Fan, S.; Zhang, T. (2008). Barium-Functionalized Multiwalled Carbon Nanotube Yarns as Low-WorkFunction Thermionic Cathodes. Appl. Phys. Lett., Vol. 92, pp. 153108.

Xiao, L.; Chen, Z.; Feng, C.; Liu, L.; Bai, Z. Q.; Wang, Y.; Qian, L.; Zhang, Y. Y.; Li, Q. Q.; Jiang, K. L.; Fan, S. S. (2008). Flexible, Stretchable, Transparent Carbon Nanotube Thin Film Loudspeakers. Nano Lett., Vol. 8, pp. 4539-4545.

Xu, F.; Lu, W.; \& Zhu, Y. (2011). Controlled 3D Buckling of Silicon Nanowires for Stretchable Electronics. ACS Nano, Vol. 5, pp. 672- 678.

Zhang, M.; Nakayama, Y.; \& Pan, L. (2000). Synthesis of Carbon Tubule Nanocoils in High Yield Using Iron-Coated Indium Tin Oxide as Catalyst. Jpn. J. Appl. Phys., Vol. 39, pp. L1242-L1244.

Zhang, M.; Atkinson, K. R.; \& Baughman, R. H. (2004). Multifunctional carbon nanotube yarns by downsizing an ancient technology. Science, Vol. 306, pp.1358-1361.

Zhang, M.; Fang, S.; Zakhidov, A. A.; Lee, S. B.; Aliev, A. E.; Williams, C. D.; Atkinson, K. R.; \& Baughman, R. H. (2005). Strong, Transparent, Multifunctional Carbon Nanotube Sheets. Science, Vol. 309, pp. 1215-1219.

Zhang, M. \& Li, J. (2009). Carbon Nanotube in Different Shapes. Materials Today, Vol. 12, pp. 12-18.

Zhang, T.; Mubeen, S.; Myung, N.; \& Deshusses, M. (2008) Recent progress in carbon nanotube-based gas sensors. Nanotechnology, Vol. 19, pp. 332001-14.

Zhang, H.; Feng, C.; Zhai, Y.; Jiang, K.; Li, Q.; \& Fan, S. (2009). Cross-Stacked Carbon Nanotube Sheets Uniformly Loaded with $\mathrm{SnO}_{2}$ Nanoparticles: A Novel Binder-Free and High-Capacity Anode Material for Lithium-Ion Batteries. Adv. Mater. Vol. 21, pp. 2299-2304.

Zhang, X.; Jiang, K.; Feng, C.; Liu, P.; Zhang, L.; Kong, J.; Zhang, T.; Li, Q.; \& Fan, S. (2006). Spinning and Processing Continuous Yarns from 4-Inch Wafer Scale Super-Aligned Carbon Nanotube Arrays. Adv. Mater., Vol. 18, pp. 1505- 1510.

Zhong, G.; Hofmann, S.; Yan, F.; Telg, H.; Warner, J. H.; Eder, D.; Thomsen, C.; Milne, W. I.; \& Robertson, J. (2009). Acetylene: A Key Growth Precursor for Single-Walled Carbon Nanotube Forests. J. Phys. Chem. C, Vol. 113, pp. 17321-17325.

Zhong, X. H.; Li, Y. L.; Liu, Y. K.; Qiao, X. H.; Feng, Y.; Liang, J.; Jin, J.; Zhu, L.; Hou, F.; Li, J. Y. (2010). Continuous Multilayered Carbon Nanotube Yarns. Adv. Mater., Vol. 22, pp. 692- 696.

Zhou, Y.; Hu, L.; \& Gruner, G. (2006). A method of printing carbon nanotube thin films. Appl. Phys. Lett. Vol. 88, pp. 123109.

Zhou, R.; Meng, C.; Zhu, F.; Li, Q.; Liu, C.; Fan, S.; \& Jiang, K. (2010). High-performance supercapacitors using a nanoporous current collector made from super-aligned carbon nanotubes. Nanotechnology, Vol. 21, pp. 345701. 


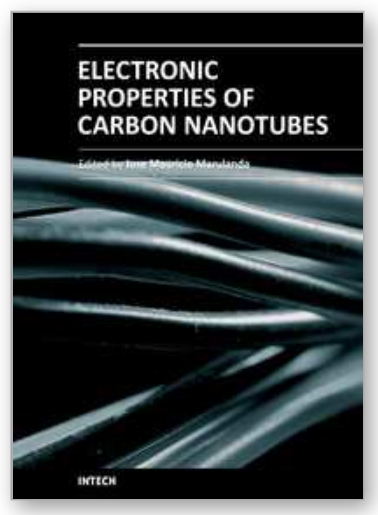

\author{
Electronic Properties of Carbon Nanotubes \\ Edited by Prof. Jose Mauricio Marulanda
}

ISBN 978-953-307-499-3

Hard cover, 680 pages

Publisher InTech

Published online 27, July, 2011

Published in print edition July, 2011

Carbon nanotubes (CNTs), discovered in 1991, have been a subject of intensive research for a wide range of applications. These one-dimensional (1D) graphene sheets rolled into a tubular form have been the target of many researchers around the world. This book concentrates on the semiconductor physics of carbon nanotubes, it brings unique insight into the phenomena encountered in the electronic structure when operating with carbon nanotubes. This book also presents to reader useful information on the fabrication and applications of these outstanding materials. The main objective of this book is to give in-depth understanding of the physics and electronic structure of carbon nanotubes. Readers of this book should have a strong background on physical electronics and semiconductor device physics. This book first discusses fabrication techniques followed by an analysis on the physical properties of carbon nanotubes, including density of states and electronic structures. Ultimately, the book pursues a significant amount of work in the industry applications of carbon nanotubes.

\title{
How to reference
}

In order to correctly reference this scholarly work, feel free to copy and paste the following:

Mei Zhang and Ray Baughman (2011). Assembly of Carbon Nanotube Sheets, Electronic Properties of Carbon Nanotubes, Prof. Jose Mauricio Marulanda (Ed.), ISBN: 978-953-307-499-3, InTech, Available from:

http://www.intechopen.com/books/electronic-properties-of-carbon-nanotubes/assembly-of-carbon-nanotubesheets

\section{INTECH}

open science | open minds

\section{InTech Europe}

University Campus STeP Ri

Slavka Krautzeka 83/A

51000 Rijeka, Croatia

Phone: +385 (51) 770447

Fax: +385 (51) 686166

www.intechopen.com

\section{InTech China}

Unit 405, Office Block, Hotel Equatorial Shanghai

No.65, Yan An Road (West), Shanghai, 200040, China

中国上海市延安西路65号上海国际贵都大饭店办公楼 405 单元

Phone: +86-21-62489820

Fax: $+86-21-62489821$ 
(C) 2011 The Author(s). Licensee IntechOpen. This chapter is distributed under the terms of the Creative Commons Attribution-NonCommercialShareAlike-3.0 License, which permits use, distribution and reproduction for non-commercial purposes, provided the original is properly cited and derivative works building on this content are distributed under the same license. 